\title{
Temporal Microbial Community Dynamics within a Unique Acid
}

\section{Saline Lake}

1 Noor-ul-Huda Ghori ${ }^{1,2^{*}}$, Michael. J. Wise ${ }^{2,3}$, Andrew. S. Whiteley ${ }^{1}$

$2{ }^{1}$ Microbial molecular and ecology group, The School of Agriculture and Environment (SAgE), The

3 University of Western Australia, Perth, WA, Australia

$4{ }^{2}$ The Marshall Centre, The School of Biomedical Sciences, The University of Western Australia,

5 Perth, WA, Australia

$6{ }^{3}$ The School of Computer Sciences and Engineering, The University of Western Australia, Perth,

7 WA, Australia

8 * Correspondence:

9 Corresponding Author

10 Noor-Ul-Huda Ghori

11 noor-ul-huda.ghori@uwa.edu.au

13 Keywords: Polyextremophile $1,16 \mathrm{~S}$ rRNA $2,18 S$ rRNA remporal microbial dynamics, $_{4}$, Acid

14 Saline 5.

15

16 


\section{Abstract}

18 Lake Magic is one of the acidic hypersaline lakes (ca. $1 \mathrm{~km}$ in diameter) present within the Yilgarn

19 Craton in WA. This unique lake exhibits extremely low $\mathrm{pH}(<1.6)$ coupled to very high salinity $(32 \%$

20 TDS) with the highest concentration of aluminium $(1774 \mathrm{mg} / \mathrm{L})$ and silica $(510 \mathrm{mg} / \mathrm{L})$ in the world.

21 Previous studies on Lake Magic diversity has revealed that the lake hosts acidophilic, acidotolerant,

22 halophilic and halotolerant bacterial species. These studies provide indicators of the population

23 residing within the lake. However, they do not emphasize the survival mechanisms adopted by the

24 resident microorganisms and how the diversity of microbial populations residing within the lake

25 changes during the dynamic stages of flooding, evapo-concentration and desiccation. We have studied

26 the bacterial and fungal diversity in Lake Magic via amplicon sequencing and functional analysis

27 through different stages of the lake in a span of one year, in the salt and sediment layer. Our results

28 highlight that the diversity in Lake Magic is strongly driven by the $\mathrm{pH}$ and salt concentrations at

29 different stages of the lake. The microbial community becomes more specialised in specific functions

30 during more extreme stages. This also suggests that microbial interactions are involved in stabilising

31 the ecosystem and is responsible for the resistance and resilience of these communities as the

32 interactions of these microbes create a safe haven for other microbes to survive during more extreme

33 stages. 


\section{Diversity dynamics of Lake Magic}

\section{$36 \quad 1$ Introduction}

37 Acid saline lakes represent one of the most extreme aquatic environments on Earth. They are poly38 extreme ecosystems, exhibiting extremely acidic $\mathrm{pH}$ and salinities close to saturation. Such

39 environments are of significant microbial interest as they host organisms that are not only capable of

40 withstanding $\mathrm{pH}$ and salinity stress, but also survive in the presence of additional stressors such as high

41 metal concentrations and low nutrients (Mormile et al., 2007; Heidelberg et al., 2013; Johnson et al.,

42 2015; Zaikova et al., 2018). Moreover, they serve as a reservoir of novel microbial functions, such as

43 acidophilic microorganisms that have been used for extracting metal ores from sulphide minerals.

44 Hence, such environments are of significant interest to scientists interested in understanding the

45 fundamental concepts of microbial mechanisms used to cope with significant stressors, as well as

46 applied areas developing microbial consortia for bioprocessing applications (Dopson et al., 2017).

Lake Magic is one of the acidic hypersaline lakes (ca. $1 \mathrm{~km}$ in diameter) present within the Yilgarn

49 Craton in WA. This unique lake exhibits extremely low $\mathrm{pH}(<1.6)$ coupled to very high salinity $(32 \%$

50 TDS) with the highest concentration of aluminum $(1774 \mathrm{mg} / \mathrm{L})$ and silica $(510 \mathrm{mg} / \mathrm{L})$ in the world

51 (Bowen and Benison 2009; Conner and Benison, 2013). Lake Magic, similar to other lakes in WA, has

52 dynamic and characteristic stages of lake transformation, including flooding, evapo-concentration and

53 desiccation that are driven by the local seasons (Bowen and Benison 2009; Conner and Benison, 2013).

54 The lake is fed via both regional acidic groundwater and infrequent precipitation (Benison et al., 2007).

55 Recent studies of the microbial diversity of Lake Magic has revealed that the lake hosts acidophilic,

56 acidotolerant, halophilic and halotolerant bacterial species (Zaikova et al., 2018). Moreover, fluid

57 inclusions of halite crystals from Lake Magic, exhibited the presence of micro-algae and prokaryotes

58 trapped within them (Conner and Benison, 2013). More recently, metagenomic analyses of lake water,

59 groundwater and within the sediment of Lake Magic revealed that the lake is dominated by only a few 
species, such as Salinisphaera, and has a low representation of other bacterial species (Zaikova et al.,

61 2018). Interestingly, the pelagic zone of the lake was abundant in eukaryotes, including fungi and green

62 algae, giving rise to the bright yellow colour of the lake (Zaikova et al., 2018, Conner and Benison,

63 2013). These studies provide indicators of the population residing within the lake and the functional

64 niches they occupy. However, they do not emphasize the survival mechanisms adopted by the resident

65 microorganisms and how the diversity of microbial populations residing within the lake changes during

66 different transformational stages of the lake.

Molecular approaches to understand the dynamics of Yilgarn Craton lakes in the past have focused primarily on spatial composition (Mormile et al., 2009; Johnson et al., 2015; Zaikova et al., 2018; Aerts et al., 2019). However, these studies implicitly assume that a single time point can provide a comprehensive representation of the community members. In opposition, temporal approaches to study microbial community dynamics have recently revealed considerable variability within microbial community compositions over time (Ju and Zhang, 2014; Chénard et al., 2017; Nagarkar et al., 2018; Cruaud et al., 2019), showing that some taxa remain consistent in their abundance whilst others exhibit sudden blooms (Nagarkar et al., 2018).

We hypothesize that the large fluctuations in environmental parameters during lake transformations are key drivers which will lead to marked changes in microbial populations, and contribute to the mechanisms driving the dynamics of these communities (Cruaud et al., 2019). Therefore, studying the temporal dynamics of microbial communities in poly-extreme ecosystems such as Lake Magic could reveal crucial information about the trophic interactions and survival mechanisms (Nagarkar et al.,

82 2018). This study attempts to investigate the diversity and functional dynamics of bacterial, archaeal

83 (referenced as 'bacterial' from hereon) and fungal communities, over a period of one year. Using 16S 


\section{Diversity dynamics of Lake Magic}

85 transformations and assess likely mechanisms the resident microorganisms adopt in order to survive in

86 the face of multiple stressors.

\section{Materials and Methods}

89

\subsection{Sample collection}

91 Samples were collected from Lake Magic for every lake stage in a span of one year (July 2017-July

92 2018). Multiple sampling sites were chosen around the lake to eradicate a spatial sampling effect.

93 Sediment samples were taken as cores, which were divided into salt mat and sediment layers (Figure

94 1). All samples were taken with sterile cores and spatulas. After every sample the cores and spatulas

95 were sterilized with $70 \%$ ethanol. A total of 40 sediment samples and 40 salt mat samples ( 8 cores for

96 each time point) were collected. Temperature, $\mathrm{pH}$, and salinity were measured for each sampling point.

97 All samples were kept frozen at $-20^{\circ} \mathrm{C}$ in $50 \mathrm{ml}$ Falcon tubes until further processing.

\subsection{DNA extraction, PCR and amplicon sequencing}

100 DNA from sediment and salt mat samples was extracted using a method developed for acid saline

101 sediments. Briefly, $0.4 \mathrm{~g}$ sediment sample in $2 \mathrm{ml}$ tubes containing glass beads. To this $900 \mu \mathrm{l}$ of

102 extraction buffer (consisting of $0.2 \mathrm{M}$ sodium phosphate buffer, $0.2 \% \mathrm{CTAB}, 0.1 \mathrm{M} \mathrm{NaCl}$ and $50 \mathrm{mM}$

103 EDTA), $100 \mu \mathrm{l}$ of $10 \%$ SDS and $10 \mu \mathrm{l}$ of Proteinase K $(20 \mathrm{mg} / \mathrm{ml})$. The mixture was kept at $-80 \mathrm{C}$ for

$1045 \mathrm{~min}$ and then heated at $70 \mathrm{C}$ for $20 \mathrm{~min}$. The mixture was subjected to mechanical agitation at $20 \mathrm{~Hz}$

105 for $20 \mathrm{~min}$ after which the tubes were kept on ice for $5 \mathrm{~min}$. The mixture was centrifuged at $10,000 \mathrm{x}$

$106 \mathrm{~g}$ for $5 \mathrm{~min}$. To the supernatant $750 \mu \mathrm{l}$ of chilled phenol-chloroform-isoamyl ( $\mathrm{pH} 8$ ) solution was added

107 and centrifuged for $20 \mathrm{~min}$ at $10,000 \mathrm{x}$. Aqueous layer was transferred to sterile tube and $600 \mu \mathrm{l}$ of 
108 chilled chloroform -isoamyl ( $\mathrm{pH} 8)$ solution was added. The mixture was centrifuged at 10, $000 \mathrm{x} \mathrm{g}$ for

$1095 \mathrm{~min}$. Next, to the aqueous layer $650 \mu \mathrm{l}$ of $20 \% \mathrm{PEG}, 2.5 \mathrm{M} \mathrm{NaCl}$ was added and incubated at $4 \mathrm{C}$ for

110 overnight. The solution was centrifuged for $20 \mathrm{~min}$ at $10,000 \mathrm{x} \mathrm{g}$. The obtained pellet was washed

111 with $70 \%$ ice cold ethanol and $2 \mu$ glycogen. The final pellet was dissolved in $50 \mu 1$ of TE buffer. All

112 extractions were carried out in triplicate. Tubes containing no sample were incorporated as extraction

113 blanks (controls) and were treated identical to sample extractions. DNA concentration was measured

114 through fluorometry using a Qubit dsDNA HS Assay Kit with a Qubit 2.0 fluorometer (Life

115 Technologies).

117 Extracted DNA from all timepoints were diluted 10-fold prior to PCR amplification of the 16S rRNA

118 and ITS genes. All PCR reactions were carried out in triplicate. PCR amplification of the 16S rRNA

119 gene V4-V5 region was performed using the universal PCR primer set 515F and 806R, targeting 120 members within both bacterial and archaeal domains (16). The forward primer included the addition

121 of an Ion Torrent PGM sequencing adapter, a GT spacer and a unique Golay barcode to facilitate 122 multiplexed sequencing. Barcoded PCR reaction mixtures $(20 \mu 1)$ consisted of DNA template $(1 \mu \mathrm{l})$, 123 universal primer mix (untagged 515F and 806R at a final concentration of $0.2 \mu \mathrm{M}$ ), tagged 515F primer $124(0.2 \mu \mathrm{M}), 600 \mathrm{ng}$ BSA (Life technologies) and 2.5 x 5'Hot Master Mix (5Primer, Australia). The PCR 125 cycle was set at $94 \mathrm{C}$ for $2 \mathrm{~min}$ followed by 25 cycles of $94 \mathrm{~min}$ for $45 \mathrm{sec}, 50 \mathrm{C}$ for $60 \mathrm{sec}$ and $65 \mathrm{C}$ for 126 90. This was followed by 2 cycles of $94 \mathrm{C}$ for $45 \mathrm{sec}, 65 \mathrm{C}$ for $90 \mathrm{sec}$ and final extension at $65 \mathrm{C}$ for 10 $127 \min$.

129 Amplification of the fungal component was carried out using the universal primer set ITS1 F and ITS2 $130 \mathrm{R}$, with the addition of an Ion Torrent PGM sequencing adapter, a GT spacer and a unique Golay 


\section{Diversity dynamics of Lake Magic}

131 barcode to the forward primer. The barcoded PCR primer mixtures $(20 \mu 1)$ included DNA template (1

$132 \mu 1$ ), universal primer mix (untagged ITS1 F and ITS2 R at a final concentration of $0.2 \mu \mathrm{M}$ ), $600 \mathrm{ng}$

133 BSA (Life technologies), tagged ITS1 F primer $(0.2 \mu \mathrm{M})$ and $2.5 \times 5$ ' Hot Master Mix (5Primer,

134 Australia). The PCR conditions included initial denaturation at 94 for 2 min followed by 25 cycles of $13594 \mathrm{C}$ for $45 \mathrm{sec}, 50 \mathrm{C}$ for $60 \mathrm{sec}$ and $65 \mathrm{C}$ for $90 \mathrm{sec}$. This was followed by 9 cycles of $94 \mathrm{C}$ for $45 \mathrm{sec}$, $136 \quad 65 \mathrm{C}$ for $90 \mathrm{sec}$ and 65 for $10 \mathrm{~min}$.

138 Several positive, no template (as negative controls) controls and DNA extraction controls (extraction

139 blanks) were amplified along with the samples for both bacterial and fungal marker genes. PCR

140 reaction performance was checked by loading PCR amplicons along with positive and negative

141 controls on a 2\% (w/v) agarose gel. The amplicons were quantified using a Qubit dsDNA HS Assay

142 Kit on the Qubit 2.0 fluorometer (Life Technologies). All amplicons were subsequently pooled in one 143 composite mixture at a concentration of $20 \mathrm{ng} / \mu \mathrm{l}$, including negative controls. The pool was purified 144 using AMPure XP (Beckman Coulter, Australia) and the quality of the pool was checked by visualizing 145 on a $2 \%(\mathrm{w} / \mathrm{v})$ agarose gel. The composite pool was sequenced on an Ion Torrent PGM.

\section{$147 \quad 2.3 \quad$ Sequence analysis and statistical analysis}

148 Raw sequences were de-multiplexed and quality filtered through a custom QIIME pipeline

149 (Quantitative Insights into Microbial Ecology) (Caporaso et al., 2010) with a minimum average quality

150 score of 20. The minimum sequence length was maintained at 130 b.p. and maximum sequence length

151 of 350 b.p. Chimeric sequences were removed using USEARCH v6.1. No forward or reverse primer

152 mismatches or barcode errors were allowed and maximum sequence homopolymers allowed were 15. 
153 The maximum number of ambiguous bases was set at six. Denovo OTU picking was performed using

154 ULCUST at 97\% sequence identity cut off values and taxonomy was assigned through the Greengenes

155 database (version 13.8). For fungal data, taxonomy was assigned using the SILVA v123 database

156 (Quast et al., 2012).

158 The OTU tables obtained for different levels of taxonomy were used as measures of taxa relative

159 abundance in univariate statistical analysis. The OTUs detected in negative controls were manually

160 removed from the data set. Alpha $(\alpha)$ - diversity at the phylum level for both 16S rRNA gene and ITS

161 gene data was calculated using the richness, evenness and Shannon Weiner diversity index using the

162 relative frequency table generated from a rarefied 'biom' table. Data normality was checked with the

163 Shapiro-Wilk test and log transformations of the data were performed where appropriate. Differences

164 in the diversity for each stage and layer (sediment, salt mat), was calculated using a two-way analysis

165 of variance (ANOVA). Tukey HSD post hoc comparisons of groups were used to identify which groups

166 were significantly different from each other.

168 Beta diversity $(\beta)$ of microbial communities was calculated with nonmetric multidimensional scaling

169 (nMDS) using Bray-Curtis dissimilarity (Bray and Curtis, 1957). Statistical significances of

170 dissimilarity, based on temporal data and sample layer, was assessed using main effect and pairwise

171 ANOSIM in R using the vegan package.

172

173 Phylogeny was inferred using Phylosift (Darling et al., 2014) for sequences that could not be classified

174 past the domain level. The OTU abundance and diversity patterns were calculated using the vegan

175 package (Dixon, 2003) in R software (R Core Team, 2014). Plots and heat maps were produced using

176 'ggplot2' (Wickham, 2011), 'ggpubr' packages in R and the online suite 'Calypso' (Zakrzewski et al., 177 2017). 


\section{Diversity dynamics of Lake Magic}

178 Predicted microbial functions of the bacteria residing within Lake Magic were generated using

179 FAPROTAX, using default settings. FAPROTAX is a manually constructed database that maps the 180 microbial taxa to metabolic functions (Louca et al., 2016). The output from FAPROTAX was 181 visualised in $\mathrm{R}$ using the ggplot2 package.

\subsection{Chemical analysis}

184 Ten grams of sediment sample for each time point was oven dried at $60^{\circ} \mathrm{C}$ until completely desiccated.

185 The sample was crushed, sieved, packed in plastic bags and sent to the School of Agriculture and 186 Environment (SAgE), University of Western Australia (UWA) chemical analysis laboratory. The 187 analytical analysis included analysis of phosphorus, potassium, sulfur, organic carbon, nitrogen, iron, 188 copper, sodium, boron, calcium, zinc, aluminum, magnesium and manganese. Concentrations were 189 expressed as percentage per weight and $\mathrm{mg} / \mathrm{kg}$.

\section{Results}

\section{$192 \quad 3.1$ Lake stages and physico-chemical parameters}

193 A total of 5 time points representing 5 different stages of Lake Magic were sampled for this study.

194 Although the lake did not go through some of the more extreme physical changes during the year, the

195 transformation of one stage to the next was evident. Namely, we observed flooding, early evapo-

196 concentration, mid evapo-concentration, late evapo-concentration and early flooding in the lake

197 (Figure 2) details of which are presented in Table 1 and Table 2. During the span of this study the 198 lake did not reach complete desiccation due to heavy rainfall from 2017 to 2018.

200 The first sampling point was during late winter to early summer in 2017 , where the lake was filled with 201 several centimeters of clear blue water (July 2017) (Figure 2A). The lake sediment was rich in clay 
and a small amount of wet salt mat sample was acquired. In October 2017, the lake became shallower

(Figure 2B) during early evapo-concentration (Table 1), characterized by clear water but where halite

precipitation was evident on the lake shore. The lake transformed into a shallow yellow lake during

January 2018 sampling (Figure 2C) where the surroundings of the lake were rich in halite precipitation,

the lake itself exhibited a pungent acidic odour and the salt mat became desiccated and substantial.

During mid-summer (March 2018) the lake bed became dry and a thick salt crust was observed on the

surface of the sediment (Figure 2D) with visible salt crystals (Figure 1), constituting the late evapo-

concentration stage. At this stage the lake was also rich in iron oxide precipitation, which was evident

due to its distinct colour. The final sampling timepoint was the beginning of the flooding stage in July

2018 (Figure 2E) where the lake started to fill with water, with a concomitant dissolving of the halite

and iron precipitation observed during the evapo-concentration stages. The chemical data has been

summarized in Table 2.

\subsection{Temporal dynamics of the Lake Magic microbiome}

In order to assess the microbial community dynamics in the lake at different stages, we used 16S rRNA

gene and ITS gene Ion Torrent sequencing (15 Salt mats; 15 Sediments) in triplicate. After DNA

218 extraction, all samples had detectable amounts of DNA, but the DNA concentration was consistently

219 higher for salt mat samples when compared to the sediment samples. However, there was no significant

220 difference (ANOVA $\mathrm{p}>0.05$ ) between diversity and richness indices of salt mat and sediment layers

221 for both bacteria and fungi analyses (Supplementary Figure 1), likely indicating minimal diversity

222 analysis bias despite wide variations in DNA extraction concentrations. Generally, we found DNA

223 extraction easier from salt mat samples, relative to sediment samples, due to the lower amount of clay

224 present in the salt mat samples. 


\section{Diversity dynamics of Lake Magic}

226

227

228

229

230

231

232

233

A total of 330,913 reads were obtained for 16S rRNA microbiome analyses, representing 15947 OTUs. The OTUs were assigned to 37 phyla, 135 classes, 260 orders, 426 families and 739 genera of archaea and bacteria. Only OTUs which appeared in sequenced negative controls were discounted from the analyses and no other OTUs were filtered. This is because low abundance OTUs can have a significant effect on the diversity metrics for the microbial communities in low biomass environments, hence, filtering of OTUs with low representation in the microbiome can result in loss of crucial information. Analysis of the ITS gene sequences revealed a total of 724,490 reads, representing 4005 OTUs and were assigned to 15 phyla, 44 classes, 86 order, 177 family and 259 genera.

\subsection{Bacterial communities are dynamic in Lake Magic}

The Lake Magic microbiome OTU richness was analyzed for salt mat and sediment samples (Figure 3A) at phylum level which varied significantly between the five stages of the lake (ANOVA p=0.001). The richness index varied from 9 to 23 for $16 \mathrm{~S}$ rRNA gene and the OTU richness was significantly higher during the EF stage (mean richness $=21$ ). The second highest OTU richness was observed during the ME stage (mean richness = 18). The LE stage showed the lowest mean richness of 13.6, whereas, OTU richness at the FL stage was significantly different and showed a mean richness of 16. A mean richness of 15.5 was seen during EE stage.

The Lake Magic microbiome diversity varied during the different lake stages (Figure 3B) and followed a similar trend to that of OTU richness. The Shannon diversity index ranged from 1.61 to 2.13 for bacterial communities, where the diversity was seen to increase during EE (mean diversity $=1.65$ ) and the ME stage (mean diversity $=1.87$ ). However, the diversity decreased during the LE stage and was recorded as the lowest diversity index (mean diversity=1.39) of all stages. The highest diversity was seen during the EF stage (mean diversity=2.11). The ANOVA test was further analyzed with a Tuckey post hoc test for diversity and richness indices, which revealed that the diversity during FL, LE and EF 
stages were significantly different from each other, whereas, the richness was significantly different only during FL and EF stages.

The Lake Magic bacterial composition under different lake stages was analyzed and are shown in

(Supplementary Figure 2). Archaeal community diversity in the microbiome was represented by only

two phyla, the Crenarchaeota and the Euryarchaeota, whilst the bacterial domain contributed the

dominant microbial sequences observed within the 16S rRNA gene analyses. The majority of the

most of which could not be classified below family level, indicating that a large proportion of the bacterial taxa in Lake Magic appear to be relatively poorly characterized.

\subsection{The bacterial community becomes more specialized as stress increases}

263 For taxa which could be classified to genera, varying trends were observed during different lake stages

264 and within the sample layers (Supplementary Figure 3). Specifically, key bacterial genera fluctuated within the salt mat and sediment during the various lake stages. The correlation analysis of chemical data with the bacterial diversity revealed that microbial dynamics is strongly driven by salinity, temperature, $\mathrm{pH}$ and carbon content in the lake (Supplementary Figure 4). For instance, members of the Acidiphilium genus were low in abundance during the FL stage in both the salt mat and sediment samples, whilst their relative abundance was seen to increase within in the salt mat during evapo$\mathrm{p}<0.05)$ in Acidiphilium relative abundance was observed within the salt mat during the LE stage and significantly decreased during the EF stage of the lake (Supplementary Figure 3, Acidiphilium). 


\section{Diversity dynamics of Lake Magic}

276

277

278

279

280

281

282

283

284

285

286

287

288

289

290

291

292

293

294

295

abundance decreased when the lake was in the EF stage. In contrast, sequences belonging to the Arthrobacter, Bacillus, Flavbacterium and Sporosarcina genera increased significantly in abundance during the EF stage in both the sediment and salt mat, whilst genera such as Nitrososphaera were only present during the EF stage in high abundance.

Interestingly, it was also observed that the abundance of the Sulfurimonas, Syntrophobacter, Halothiobacillus, Acidobacterium, Acidiphilium and Alicyclobacillus genera decreased during the EF stage in both the salt mat and the sediment whilst, the Syntrophobacter population increased in relative abundance within the sediment during LE. During the FL stage Salinisphaera was found to be more abundant in the salt mat when compared to the sediment. However, when compared to the LE, its abundance increased in the salt mat (Supplementary Figure 3). Overall, from these data it was evident that the sediment becomes more dominated by bacteria that were not specialized for surviving in the environmental conditions, whereas, the salt mat became dominated with specialized microbes such as Salinisphaera and Acidobacterium.

\subsection{The fungal community becomes less diverse under extreme conditions within Lake Magic}

The diversity and richness of the fungal community within Lake Magic significantly decreased (ANOVA, $\mathrm{p}<0.001$ ) as the lake conditions became more extreme. The richness index ranged from 2 to 7 whereas the Shannon diversity index ranged from 0.004 to 1.28 (Figure 4A and 4B). The highest mean richness was observed for the FL and EE stage. The OTU richness consistently decreased after the EE stage, with lowest OTU richness observed for the EF stage (mean richness = 2). The fungal diversity showed a varying trend when compared to OTU richness, where the highest diversity index was observed for the FL stage (mean diversity index $=1.11$ ) whereas the lowest was observed for the extreme EF stage (mean diversity index=0.28). A Tuckey post hoc test revealed that the FL and EE stage were statistically similar to each other, whilst, the ME and LE stages were statistically similar, 
and the EF stage was significantly different from all other stages. Additionally, a Tuckey test for OTU richness showed that the FL, EE and EF stages were significantly different from all other stages.

304 Interestingly, when the fungal community composition was visualized (Supplementary Figure 5), an

305 increase in unidentified fungi belonging to the Ascomycota phylum was observed. This indicated that

306 a large portion of the fungi living in Lake Magic are likely unidentified. The salt mat during the EF

307 stage was, however, seen to be the most diverse when compared to other time points and was abundant

308 with the Cladosporium genus. Variation in the composition of other genera including Fusarium,

309 Ulocladium and Hostaea was also seen.

310

\section{$311 \quad 3.6$ Beta diversity of the bacterial and fungal communities}

312 The dissimilarity between microbial communities at different lake stages was assessed using

313 Nonmetric multidimensional scaling (nMDS) and Bray-Curtis dissimilarity indices. The sediment and

314 salt mat bacterial communities from the FL, ME, LE and EF stages tightly clustered together (Figure

315 5A). In contrast, the salt mat and sediment communities under the EE stage clustered separately

316 (ANOSIM, $\mathrm{R}^{2}=0.49, \mathrm{p}=0.001$ ). However, similar to alpha diversity, when an ANOSIM test was

317 applied to determine the variability in the salt mat and sediment samples no significant difference was 318 observed.

320 The nMDS analysis of fungal communities showed less clustering when compared to the bacterial

321 community analysis (Figure 5B), where none of the lake stages clustered separately. This indicated

322 that the members identified within the Ascomycota phylum vary for different lake stages (ANOSIM, $\left.323 \mathrm{R}^{2}=0.462, \mathrm{p}=0.001\right)$, but no significant difference was seen between sediments or salt mat samples. 


\section{Diversity dynamics of Lake Magic}

\subsection{Predicted ecological functions of the bacterial communities}

The ecological function of the bacterial communities analyzed was predicted using the FAPROTAX pipeline for the different stages of the lake. These analyses indicated aerobic chemoheterotrophy, iron oxidation and sulphur related pathways as likely dominant functions within the lake's bacterial community (Figure 6). Functions related to carbon metabolism, such as methylotrophy and methanotrophy, were predicted but were not abundant. Nitrogen related functions included nitrification and ammonia oxidation and were observed to fluctuate between different lake stages. For instance, these data indicated that nitrification and ammonia oxidation were significantly higher within the salt mat during the EF stage (Supplementary Figure 6). Interestingly, the nitrogen related activity was also high in the sediment samples during the EE and ME lake stage. Sulphur related functions were lower during the EF stage, but significantly increased in the sediment layer during all evapoconcentration stages. Sulphur related activity was found to be highest in the sediment during the EE stage. Iron oxidation and reduction was relatively low at all timepoints, but significantly increased during the EE and LE stage within the sediment layer. Finally, Iron based respiration pathways fluctuated more frequently when compared to sulphur and nitrogen related functions during all lake stages (Supplementary Figure 6).

\section{Discussion}

Acid saline lakes in WA host unique microorganisms that can be studied to understand life under extreme conditions, novel biogeochemical processes and new biotechnological avenues (Benison et $a l ., 2007)$. In this chapter, the bacterial and fungal microbial community dynamics were studied using a temporal approach to resolve how an extreme lake microbiome changes during different stress phases due to changes in the physico-chemical properties of the habitat. 
Previous studies on acidic hypersaline lakes in WA revealed a high level of bacterial diversity within

351 Lake Magic and other WA lakes water (Mormile et al., 2009; Zaikova et al., 2018), but have relied

352 upon single time (lake stage) sampling points. Our results indicate that the alpha ( $\alpha$ )-diversity of the

353 bacterial and fungal microbial communities differed significantly between the less extreme (FL) stage

354 and the more extreme (LE) stage. These differences indicated that the lake microbiome diversity is

355 driven to a large degree by the high salt and low $\mathrm{pH}$ conditions within the lake (Podell et al., 2014). It

356 has previously been reported for hypersaline environments that the ionic concentration in these

357 environments hinders the solubility of oxygen, and hence, the oxygen concentration is very low in acid

358 saline lakes (Sherwood et al., 1991). However, the majority of microorganisms isolated from

359 hypersaline environments are aerobic heterotrophs who are capable of anaerobic facultative

360 fermentation (Dyall-smith, 2009). Our results are also in line with these previous findings. Moreover,

361 our results show that the number of OTUs in the salt mat layer were consistently higher in all samples.

362 These results are also similar to the results obtained by Aerts et al., (2019), for four acid saline lakes

363 in Western Australia, and suggest that the majority of the microbial community diversity resides in the

364 salt mat, where it likely has increased access to light, water and oxygen. This is likely explained by the

365 availability of oxygen at the air/water interface, which exhibits an unequal distribution of oxygen

366 between the salt mat and the sediment layer. Since the salt mat is directly in contact with the water

367 column in the lake there is higher availability of oxygen locally (Podell et al., 2014). Comparing the

368 microbial composition of the salt mat and sediments in Lake Magic also indicates that microorganisms

369 more tolerant to high salt and $\mathrm{pH}$ conditions are selected within the salt mat, where the conditions are

370 harsher than those in the sediment.

372 The prokaryotic community at all stages of the lake cycle was dominated by halotolerant and

373 acidophilic microorganisms, whilst archaeal taxa were found in much lower abundances. Archaeal

374 sequences were derived from only two phyla and these observations are in good agreement with 


\section{Diversity dynamics of Lake Magic}

375 Johnson et al., (2015) who observed low archaeal diversity within four acidic hypersaline lakes in

376 Yilgarn Craton. It has been reported for Lake Tyrell in Victoria, Australia, that succession of different

377 microorganisms is dependent upon the solutes present in the lakes (Podell et al., 2014). Hence, the

378 variation in solute concentration in Lake Magic at different stages is likely driving the succession of

379 archaea and bacteria. It could also be hypothesised that bacterial taxa outcompete archaeal taxa in these

380 unique environments because of the dynamic nature of the WA lakes, where environmental changes

381 are frequent and, therefore, stress tolerant species are selected, as opposed to obligate archaeal

382 extremophiles (Benison and Bowen, 2006).

384 Organic carbon and nitrogen values were found to be low at all lake stages and increased slightly during

385 the flooded (FL) stages, in line with previous studies in similar lakes in WA (Ruecker et al., 2016;

386 Aerts et al., 2019). Similarly, phosphorus levels were also low in Lake Magic, as in other WA lakes

387 (Aerts et al., 2019), with phosphorus often being considered a limiting factor along with carbon and

388 nitrogen for the growth of microorganisms (Elser et al., 2007). Microbiome community analyses

389 indicated an abundant community of heterotrophs within the lake and hence, low carbon, nitrogen and

390 phosphorus are likely to be responsible for the low the biomass in these samples (Aerts et al., 2019).

391 However, carbon and nitrogen levels were highest during the ME and these increases are likely due to

392 photosynthetic inputs via blooming of the saline tolerant algae Dunaliella. This is also reflected in the

393 increased microbial diversity during the ME stage. Blooming of algae commonly occurs during this

394 lake stage and provides a source of photosynthetically derived nutrient input which causes increased

395 diversity in the lake (Zaikova et al., 2018).

397 During the evapo-concentration stages iron concentrations increased which was also mirrored in the 398 predicted microbiome functions of increased iron respiration activity within the bacterial community.

399 Iron metabolism is considered an important function of the sediment inhabitants and is thought to be 
responsible for the lowering of $\mathrm{pH}$ in the sediment ( $\mathrm{Lu}$ et al., 2016; Zaikova et al., 2018). The

401 Alicyclobacillus genus members are reported to be involved in iron oxidation along with archaea in

402 other acid saline lakes in WA (Johnson et al., 2015; Lu et al., 2016). The members of the genus are

403 also capable of reducing iron (Yahya et al., 2008; Lu et al., 2010). Previous metagenomic studies of

404 Lake magic indicated that Alicyclobacillus was the most abundant genus within the sediment.

405 Moreover, the Acidiphilium genus was also found to be abundant in the sediment samples (Zaikova et

$406 a l ., 2018)$ with members of this genus are involved in iron reduction (Weber et al., 2006; Sánchez-

407 Andrea et al., 2011; Zaikova et al., 2018).

These data indicated, that the abundance of the Alicyclobacillus and Acidiphilium genera varied across

different lake stages and is likely more complicated than first thought, in terms of lake biogeochemistry

411 (Zaikova et al., 2018). Alicyclobacillus abundance was significantly higher in sediment samples during

412 the FL stage and was significantly increased during the EE stage within the salt mat samples. In contrast

413 the, Acidiphilium genus was more abundant within the salt mat samples during the later LE stage.

414 Interestingly the overall abundance of these genera decreased during the higher stress stages of the

415 lake. Previously it has been suggested that archaea dominate iron oxidation in acid saline extreme

416 environment and that the role of bacteria is limited. Moreover, the Iron activity is known to decrease

417 by the presence of high salt in the environment (Lu et al., 2016). In the study, Acidiphilium spp. were

418 isolated from an acid saline lake in WA which formed long filamentous structures during low $\mathrm{pH}$ and

419 high salinity conditions indicating that these species have developed a coping mechanism for extreme

420 stress (Lu et al., 2016). Examining the functional profile of our samples it can be seen that predicted

421 iron respiration would increase significantly in the sediment during the EE and LE stage and is the

422 lowest in the sediment during the FL stage potentially because of the coping mechanism adapted by

423 these species. 


\section{Diversity dynamics of Lake Magic}

425 The activity of acidophiles is known to decrease significantly in presence of high concentration of

426 chloride ions (Suzuki et al., 1999; Shiers et al., 2005). However, Lu et al., (2016) found that

Acidiphilium spp. formed long filaments as a coping mechanism to high chloride ions within the

428 Dalyup river in WA. These data, in concert with previous results, suggest that iron metabolism is

429 affected by the presence of chloride ions and we hypothesise that this may explain the bacterial spp. of

430 Alicyclobacillus and Acidiphilium being dominant during EE and FL stages. These data also suggest

431 that under the high chloride conditions, based upon community data, these species are responsible of

432 lowering the $\mathrm{pH}$ in the sediment. Hence, we postulate from these results that microorganisms in Lake

433 Magic adapt to stressful conditions of $\mathrm{pH}$ and salinity not only physiologically, but also play crucial

434 roles in changing their external environment making it more habitable for themselves and other

435 members of the Lake.

437 One of the most abundant genera detected in these data was the Salinisphaera (7\%), in both the 438 sediment and salt mat. Salinisphaera species are mesophilic, halotolerant and slightly acidophilic $(\mathrm{pH}$ range 5.0-7.5), surviving in a range of moderately acidic and saline conditions as well as high concentrations of metal ions. Species belonging to the Salinisphaera genus have been isolated from a

441 range of environments, including hydrothermal vents, solar salterns, brine from salt wells, seawater

442 and marine fish surfaces (Antunes et al., 2003; Mormile et al., 2007; Crespo-Medina et al., 2009; Bae 443 et al., 2010; Gi et al., 2010; Park et al., 2012; Zhang et al., 2012; Shimane et al., 2013). Critically, 444 these species are able to metabolize both autotrophically and heterotrophically (Antunes et al., 2003;

445 Crespo-Medina et al., 2009; Bae et al., 2010; Antunes et al., 2011a; Park et al., 2012; Zhang et al., 2012; Shimane et al., 2013). In addition, Salinisphaera species are also involved in the uptake of iron and siderophore production (Antunes et al., 2003). Molecular studies here indicated that the abundance 448 of Salinisphaera was consistently high in salt mats during all lake stages, except during the flooded 449 (FL) stage, where it was more abundant within the sediment. Salinisphaera was previously reported to 
be the single most dominant OTU in the lake water (Zaikova et al., 2018) during evapo-concentration

451 in Lake Magic. These findings together indicate that most of the Salinisphaera spp. reside in the water

452 column of Lake Magic. The dramatic increase in its representation during the LE stage in the salt mat

453 and sediment suggests that it is highly tolerant of extreme $\mathrm{pH}$ and acidic environmental conditions,

454 including tolerance to heavy metal ions, allowing it to survive through the evapo-concentration stages.

456 Members of the Sulfurimonas genus have been isolated from diverse environments such as 457 hydrothermal vents, marine sediments and terrestrial habitats and are known to play an important role 458 in chemoautotrophic processes (Han and Perner, 2015). The members of this genus can grow on a 459 variety of electron donors and acceptors and, thus, are able to colonize disparate environments. These 460 include different reduced sulphur compounds such as sulphide, elemental sulphur, sulphite and 461 thiosulfate (Han and Perner, 2015). Many members of the genus are also involved in nitrogen and 462 hydrogen metabolism. In our samples, Sulfurimonas (1.2\%) abundance continuously decreased in salt 463 mats but increased in abundance within the sediments as the environmental conditions became more 464 stressful. Ultimately, it decreased significantly during the most extreme (LE) lake stages but still 465 maintained a low representation in the sediment. When examining the functional profile data, sulphur 466 respiration significantly increased in the sediment samples during the evapo-concentration stages, 467 suggesting that Sulfurimonas spp play a crucial role in cycling key nutrients in the sediment. Since the 468 members of the genus are able to survive chemolithoautotrophically using various electron acceptors 469 and donors (Campbell et al., 2006; Grote et al., 2008), it suggests that these species are capable of 470 adapting to the changing environmental conditions of Lake Magic. A similar trend of abundance was seen for Flavobacterium, Bacillus and Syntrophobacter genera where their abundances increased in

472 the sediment during the evapo-concentration stages and we postulate that they play a crucial role in 473 niche construction by interacting with other dominant taxa as the stress increases. 


\section{Diversity dynamics of Lake Magic}

474 The fungal diversity was seen to decrease as the environmental conditions became more extreme. A

475 single phylum, Ascomycota $(76.8 \%)$ became dominant as the lake became dry and hypersaline. Most

476 of the members of this phylum are unidentified, and hence, most of the fungi residing in Lake Magic

477 are either novel, or the sequence length of the marker gene used in this study is not sufficient to be able

478 to characterise these members. It can be deduced that these fungi are tolerant of the acidic hypersaline

479 conditions of the lake. In a previous study on Lake Magic microbiology, the water samples were found

480 to be highly diverse in terms of eukaryotic community composition, being abundant $(\sim 98.5 \%)$ in

481 Ascomycota. Aspergillus and Penicillium were the most abundant genera in Lake Magic water.

482 However, the results for sediment samples were quite similar to our results (Zaikova et al., 2018). The

483 presence of the halotolerant algae Dunaleilla during evapo-concentration stages is a major contributor

484 to carbon content in the lake. It can be deduced from the data that as Dunaleilla increase in the Lake

485 (during ME) the diversity in the salt mat increases rapidly. Interestingly, this difference in the diversity

486 of lake water and sediment column indicates the exchange between the two compartments in terms of

487 nutrition. The water column is more abundant in oxygen and has access to sunlight whilst, the higher

488 composition of eukaryotes in the water column which contribute to the carbon and nitrogen content in

489 the salt mat and the sediment.

490

491 In conclusion, our results highlight that the diversity in Lake Magic is strongly driven by the $\mathrm{pH}$ and

492 salt concentrations at different stages of the lake. In both the salt mat and sediment samples, bacteria

493 were found to be more abundant in the lake, comprising of halotolerant and acidotolerant species and

494 only a small representation of archaea was seen. We can conclude from our results that, the sediment

495 was seen to become more specialised in microorganisms involved in buffering their external

496 environment, evident from the increase in abundance of acidotolerant and halotolerant species involved

497 in various functions such as sulphur and iron metabolism. Moreover, due to microbial activity the

498 environmental conditions do not change to the same degree in the sediment when compared to the salt 
499 mat, resulting in a safe haven for microbes, where they are able to thrive during extreme conditions.

500 These findings confirm our hypothesis that during stressed conditions, microorganisms extensively

501 rely on associations with other microorganisms and the interactions increasingly become positive

502 (Piccardi et al., 2019). This also suggests that microbial interactions are involved in stabilising the

503 ecosystem and is responsible for the resistance and resilience of these communities (Zengler and

504 Zaramela, 2018; Naidoo et al., 2019). 


\section{References}

507 Aerts JW, van Spanning RJM, Flahaut J, Molenaar D, Bland PA, Ehrenfreund P, Martins Z (2019). Microbial Communities in Sediments From Four Mildly Acidic Ephemeral Salt Lakes in the Yilgarn Craton (Australia) - Terrestrial Analogs to Ancient Mars. Front Microbiol;10:779.

Antunes A, Eder W, Fareleira P, Santos H, Huber R (2003). Salinisphaera shabanensis gen. nov., sp. nov., a novel,

Antunes A, Ngugi DK, Stingl U (2011). Microbiology of the Red Sea (and other) deep-sea anoxic brine lakes. Environ Microbiol Rep; 3(4):416-33.

Bae GD, Hwang CY, Kim HM, Cho BC (2010). Salinisphaera dokdonensis sp. nov., isolated from surface seawater. Int J Syst Evol Microbiol; 60(3):680-5.

Benison KC, Beitler Bowen B, Oboh-Ikuenobe FE, Jagniecki EA, Laclair DA, Story SL, Melanie RM, Hong B-Y (2007). Sedimentology of acid saline lakes in Southern Western Australia: newly described processes and products of an extreme environment. J Sediment Res; 77:366-88.

Benison KC, Bowen BB (2006). Acid saline lake systems give clues about past environments and the search for life on Mars. Icarus; 183(1):225-9.

Bowen BB, Benison KC (2009). Geochemical characteristics of naturally acid and alkaline saline lakes in southern Western

Bray JR, Curtis JT (1957). An Ordination of the Upland Forest Communities of Southern Wisconsin. Ecol Monogr; 27(4):325-49.

Campbell BJ, Engel AS, Porter ML, Takai K (2006). The versatile $\varepsilon$-proteobacteria: Key players in sulphidic habitats. Nature Reviews Microbiology; 4: 458-68.

Caporaso JG, Kuczynski J, Stombaugh J, Bittinger K, Bushman FD, Costello EK, Fierer N, Pena, AG, Goodrich, JK, Gordon, JI, Huttley, GA (2010). QIIME allows analysis of high-throughput community sequencing data. Nat Methods; 7(5): 335. 

(2009). Salinisphaera hydrothermalis sp. nov., a mesophilic, halotolerant, facultatively autotrophic, thiosulfateoxidizing gammaproteobacterium from deep-sea hydrothermal vents, and emended description of the genus Salinisphaera. Int J Syst Evol Microbiol; 59(6):1497-503. (Canada). Front Microbiol; 10: 2359.

Darling AE, Jospin G, Lowe E, Matsen FA, Bik HM, Eisen JA (2014). PhyloSift: phylogenetic analysis of genomes and metagenomes. PeerJ; 2:e243.

Dixon P (2003). VEGAN, a package of R functions for community ecology. J Veg Sci; 14:927-30.

Dopson M, Holmes DS, Lazcano M, McCredden TJ, Bryan CG, Mulroney KT, et al (2017). Multiple Osmotic Stress

Dyall-Smith, M. (2009) 'The Halohandbook. Protocols for haloarchaeal genetics', version 7.2.

548 Elser JJ, Bracken MES, Cleland EE, Gruner DS, Harpole WS, Hillebrand H, Jacqueline TN, Eric WS, Jonathan BS, Jennifer terrestrial ecosystems. Ecol Lett; 10(12):1135-42.

Gi DB, Chung YH, Hye MK, Byung CC (2010). Salinisphaera dokdonensis sp. nov., isolated from surface seawater. Int J Syst Evol Microbiol; 60(3):680-5.

Grote J, Jost G, Labrenz M, Herndl GJ, Jürgens K (2008). Epsilonproteobacteria represent the major portion of chemoautotrophic bacteria in sulfidic waters of pelagic redoxclines of the baltic and black seas. Appl Environ Microbiol; 74(24):7546-51.

Han Y, Perner M (2015). The globally widespread genus Sulfurimonas: versatile energy metabolisms and adaptations to redox clines. Front Microbiol; 6:989.

Heidelberg KB, Nelson WC, Holm JB, Eisenkolb N, Andrade K, Emerson JB (2013). Characterization of eukaryotic microbial diversity in hypersaline Lake Tyrrell, Australia. Front Microbiol 4:115.

Johnson SS, Chevrette MG, Ehlmann BL, Benison KC (2015). Insights from the metagenome of an acid salt lake: the role of biology in an extreme depositional environment. PLoS One 10(4):e0122869. treatment plant. ISME J;9(3):683. 


\section{Diversity dynamics of Lake Magic}

564 Louca S, Parfrey LW, Doebeli M (2016). Decoupling function and taxonomy in the global ocean microbiome. Science ;353(6305):1272-7.

Lu S, Gischkat S, Reiche M, Akob DM, Hallberg KB, Küsel K (2010). Ecophysiology of Fe-cycling bacteria in acidic sediments. Appl Environ Microbiol; 76(24):8174-83.

Lu S, Peiffer S, Lazar CS, Oldham C, Neu TR, Ciobota V, Nab O, Lillicrap A, Rosch P, Popp J, Kusel K (2016). Extremophile microbiomes in acidic and hypersaline river sediments of Western Australia. Environ Microbiol Rep; 8(1):58-67.

Mormile MR, Hong B, Adams NT, Benison KC, Oboh-Ikuenobe F. Characterization of a moderately halo-acidophilic bacterium isolated from Lake Brown, western Australia (2007). International Society for Optics and Photonics; 66940X.

Mormile MR, Hong B-Y, Benison KC (2009). Molecular Analysis of the Microbial Communities of Mars Analog Lakes in Western Australia. Astrobiology ;9(10):919-30.

Naidoo RK, Simpson ZF, Oosthuizen JR, Bauer FF (2019). Nutrient Exchange of Carbon and Nitrogen Promotes the

Nagarkar M, Countway PD, Du Yoo Y, Daniels E, Poulton NJ, Palenik B (2018). Temporal dynamics of eukaryotic microbial diversity at a coastal Pacific site. ISME J;12(9):2278-91.

Park S-J, Cha I-T, Kim S-J, Shin K-S, Hong Y, Roh D-H, Sung K-R (2012). Salinisphaera orenii sp. nov., isolated from a solar saltern. Int J Syst Evol Microbiol; 62(8):1877-83.

Piccardi P, Vessman B, Mitri S (2019). Toxicity drives facilitation between 4 bacterial species. Proc Natl Acad Sci USA; 116(32):15979-1584.

Podell S, Emerson JB, Jones CM, Ugalde JA, Welch S, Heidelberg KB, Banfield JF, Aleen EE (2014). Seasonal fluctuations

Quast C, Pruesse E, Yilmaz P, Gerken J, Schweer T, Yarza P, Peplies J, Glockner FO (2012). The SILVA ribosomal RNA gene database project: improved data processing and web-based tools. Nucleic Acids Res; 41(D1):D590-6.

R Core Team (2014). R: A language and environment for statistical computing. R Foundation for Statistical Computing, Vienna, Austria.

Ruecker A, Schröder C, Byrne J, Weigold P, Behrens S, Kappler A (2016). Geochemistry and Mineralogy of Western Australian Salt Lake Sediments: Implications for Meridiani Planum on Mars. Astrobiology;16(7):525-38. 
Sánchez-Andrea I, Rodríguez N, Amils R, Sanz JL (2011). Microbial diversity in anaerobic sediments at Río Tinto, a naturally acidic environment with a high heavy metal content. Appl Environ Microbiol; 77(17):6085-93.

Sherwood JE, Stagnitti F, Kokkinn MJ, Williams WD (1991). Dissolved oxygen concentrations in hypersaline waters. Limnol Oceanogr; 36(2):235-50.

Shiers DW, Blight KR, Ralph DE (2005). Sodium sulphate and sodium chloride effects on batch culture of iron oxidising bacteria. Hydrometallurgy; 80(1-2):75-82.

Shimane Y, Tsuruwaka Y, Miyazaki M, Mori K, Minegishi H, Echigo A, Ohta Y, Maruyama T, Grant WD, Hatada Y (2013). Salinisphaera japonica sp. nov., a moderately halophilic bacterium isolated from the surface of a deep-sea

Suzuki I, Lee D, Mackay B, Harahuc L, Oh JK (1999). Effect of various ions, pH, and osmotic pressure on oxidation of fish, Malacocottus gibber, and emended description of the genus Salinisphaera. Int J Syst Evol Microbiol;

Weber KA, Achenbach LA, Coates JD (2006). Microorganisms pumping iron: Anaerobic microbial iron oxidation and reduction. Nature Reviews Microbiology; 4:752-64.

Wickham H (2011). ggplot2. Wiley Interdiscip Rev Comput Stat; 3(2):180-5.

611 Yahya A, Hallberg KB, Johnson DB (2008). Iron and carbon metabolism by a mineral-oxidizing Alicyclobacillus-like bacterium. Arch Microbiol; 189(4):305-12.

613 Zaikova E, Benison KC, Mormile MR, Johnson SS (2018). Microbial communities and their predicted metabolic functions 614 in a desiccating acid salt lake. Extremophiles, 22(3):367-79.

615 Zengler K, Zaramela LS (2018). The social network of microorganisms - how auxotrophies shape complex communities. $616 \quad$ Nat Rev Microbiol; 16(6):383-90.

617 Zhang YJ, Tang SK, Shi R, Klenk HP, Chen C, Yang LL, Zhou Y, Li WJ (2012). Salinisphaera halophila sp. nov., a moderately halophilic bacterium isolated from brine of a salt well. Int J Syst Evol Microbiol; 62(9):2174-9. 


\section{Diversity dynamics of Lake Magic}

622

\section{3}

624

625

626

627

628

629

630

631

632

633

634

635

636

637

638

639

640

641

642

643

644

645

646

\section{Figure legends}

Figure 1: A single core of sample ( $\sim 6 \mathrm{~cm}$ long) showing the salt mat and sediment sections. The bottom figure shows the salt mat with salt crystals on the top of sediment, sampled as a separate sample.

Figure 2: Five stages of Lake Magic in a span of one-year (a) July 2017, flooded (b) October 2017, early evapo-concentration (c) January 2018, mid evapo-concentration (d) March 2018, late evapoconcentration (e) July 2018, early flooding.

Figure 3: (a) 16S rRNA gene OTU richness (ANOVA, $p=0.001$ ) and (b) Shannon diversity index (ANOVA, $\mathrm{p}<0.001$ ) at phylum level. The letters show significant differences as obtained with Tuckey post hoc test. Colours represent: $\bigcirc$ Sediment $\bigcirc$ Salt mat.O FL O EE OME.OLE OEF

Figure 4: (a) ITS gene OTU richness (ANOVA, $p=0.001$ ) and (b) Shannon diversity index (ANOVA, $\mathrm{p}<0.001)$ at phylum level. The letters show significant differences as obtained with Tuckey post hoc test. Colours represent: $\bigcirc$ Sediment $\bigcirc$ Salt mat OFLO EE OMEO LEO EF

Figure 5: Beta diversity of (A) 16S rRNA (B) ITS sequences for different time points and layers. Samples are coloured according to the time points and shaped according to the layer

Figure 6: Dot plot showing the FAPROTAX predicted functions of the bacterial community within the salt mat and sediment samples at different lake stages.

(1)

(1)




\begin{tabular}{|c|c|c|c|c|c|c|}
\hline $\begin{array}{l}\text { Sample } \\
\text { code }\end{array}$ & $\begin{array}{l}\text { Date } \\
\text { collected }\end{array}$ & Lake stage & $\mathbf{p H}$ & EC & Temperature $\left({ }^{\circ} \mathrm{C}\right)$ & Lake description \\
\hline FL & July 2017 & Flooded & $\begin{array}{l}4.5^{*} \\
4.2^{\wedge}\end{array}$ & $\begin{array}{l}7 * \\
73.5^{\wedge}\end{array}$ & 16 & $\begin{array}{l}\text { Clear blue lake } \\
\text { water, very thin salt } \\
\text { mat layer }\end{array}$ \\
\hline $\mathrm{EE}$ & $\begin{array}{l}\text { October } \\
2017\end{array}$ & $\begin{array}{l}\text { Early evapo- } \\
\text { concentration }\end{array}$ & $\begin{array}{l}4.5^{*} \\
4.1^{\wedge}\end{array}$ & $\begin{array}{l}11.3^{*} \\
78.3^{\wedge}\end{array}$ & 25 & $\begin{array}{l}\text { Shallow blue water, } \\
\text { salt mat becomes } \\
\text { more evident }\end{array}$ \\
\hline $\mathrm{ME}$ & $\begin{array}{l}\text { January } \\
2018\end{array}$ & $\begin{array}{l}\text { Mid evapo- } \\
\text { concentration }\end{array}$ & $\begin{array}{l}4.5^{*} \\
3.4^{\wedge}\end{array}$ & $\begin{array}{l}15.95^{*} \\
146.9^{\wedge}\end{array}$ & 28 & $\begin{array}{l}\text { Yellow slime water, } \\
\text { salt foams forms on } \\
\text { the lakeshore, thick } \\
\text { salt mat layer } \\
\text { develops, strong } \\
\text { pungent smell in the } \\
\text { air }\end{array}$ \\
\hline LE & $\begin{array}{l}\text { March } \\
2018\end{array}$ & $\begin{array}{l}\text { Late evapo- } \\
\text { concentration }\end{array}$ & $\begin{array}{l}4.2^{*} \\
2.7^{\wedge}\end{array}$ & $\begin{array}{l}41.8^{*} \\
223.8^{\wedge}\end{array}$ & 33 & $\begin{array}{l}\text { A thick layer of salt } \\
\text { mat with visible } \\
\text { halite precipitation } \\
\text { as crystals }\end{array}$ \\
\hline $\mathrm{EF}$ & July 2018 & Early flooding & $\begin{array}{l}4.8^{*} \\
3.41^{\wedge}\end{array}$ & $\begin{array}{l}55.9^{*} \\
226.7^{\wedge}\end{array}$ & 24 & $\begin{array}{l}\text { Salt mat intact, water } \\
\text { fills the dry lake bed, } \\
\text { clear blue water }\end{array}$ \\
\hline
\end{tabular}

647 Table 1: Description of sampling site at different sampling time points $(*$ sediment, $\wedge$ lake water $),(\mathrm{EC}$ calculate in $\mathrm{mS} / \mathrm{cm})$ 


\section{Diversity dynamics of Lake Magic}

649

\begin{tabular}{|c|c|c|c|c|c|c|c|c|c|c|c|c|c|c|c|}
\hline Stage & $\begin{array}{l}\text { Sampling } \\
\text { time }\end{array}$ & $\begin{array}{l}\% \\
\text { Carbon }\end{array}$ & $\begin{array}{l}\% \\
\text { Nitrogen }\end{array}$ & $\begin{array}{l}\text { Al } \\
(\mathrm{mg} / \mathrm{kg})\end{array}$ & $\begin{array}{l}\text { B } \\
(\mathrm{mg} / \mathrm{kg})\end{array}$ & $\begin{array}{l}\mathrm{Ca} \\
(\mathrm{mg} / \mathrm{kg})\end{array}$ & $\begin{array}{l}\mathrm{Cu} \\
(\mathrm{mg} / \mathrm{kg})\end{array}$ & $\begin{array}{l}\mathrm{Fe} \\
(\mathrm{mg} / \mathrm{kg})\end{array}$ & $\begin{array}{l}\text { K } \\
(\mathrm{mg} / \mathrm{kg})\end{array}$ & $\begin{array}{l}\text { Mg } \\
\text { (mg/kg) }\end{array}$ & $\begin{array}{l}\text { Mn } \\
(\mathrm{mg} / \mathrm{kg})\end{array}$ & $\begin{array}{l}\mathrm{Na} \\
(\mathrm{mg} / \mathrm{kg})\end{array}$ & $\begin{array}{l}P \\
(\mathrm{mg} / \mathrm{kg})\end{array}$ & $\begin{array}{l}\mathrm{S} \\
(\mathrm{mg} / \mathrm{kg})\end{array}$ & $\begin{array}{l}\mathrm{Zn} \\
(\mathrm{mg} / \mathrm{kg})\end{array}$ \\
\hline Early & July 2018 & 1.56 & 0.064 & 1186 & 6.8 & 10790 & 0.7 & 33 & 781 & 2661 & 1.5 & 33759 & 7.4 & 9190 & 0.2 \\
\hline
\end{tabular}

flooding

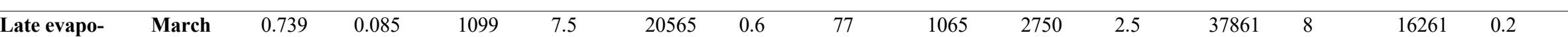

concentration

2018

\begin{tabular}{|c|c|c|c|c|c|c|c|c|c|c|c|c|c|c|c|}
\hline $\begin{array}{l}\text { Mid evapo- } \\
\text { concentration }\end{array}$ & Jan 2018 & 1.30 & 0.088 & 1256 & 5.7 & 2750 & 0.6 & 52 & 598 & 1462 & 1.5 & 19260 & 12 & 2591 & 0.2 \\
\hline Early evapo- & Oct 2017 & 0.597 & 0.061 & 1023 & 3.6 & 11308 & 0.4 & 47 & 357 & 733 & 0.9 & 9526 & 10 & 8716 & 0.1 \\
\hline
\end{tabular}

concentration

Flooding July $2017 \quad 1.01 \quad 0.062$ 1007 350 64 $323 \quad 587$ $0.6 \quad 7056$ $6 \quad 488$

Table 2: Chemical data for samples at different time points. All values shown are assessed using a single sample at each time point. 
Diversity dynamics of Lake Magic

666

668

669

670

671

672

673

674

675

676

677

678

679

680

681

682 
bioRxiv preprint doi: https://doi.org/10.1101/2020.12.17.423355; this version posted December 18, 2020. The copyright holder for this preprint (which was not certified by peer review) is the author/funder. All rights reserved. No reuse allowed without permission.

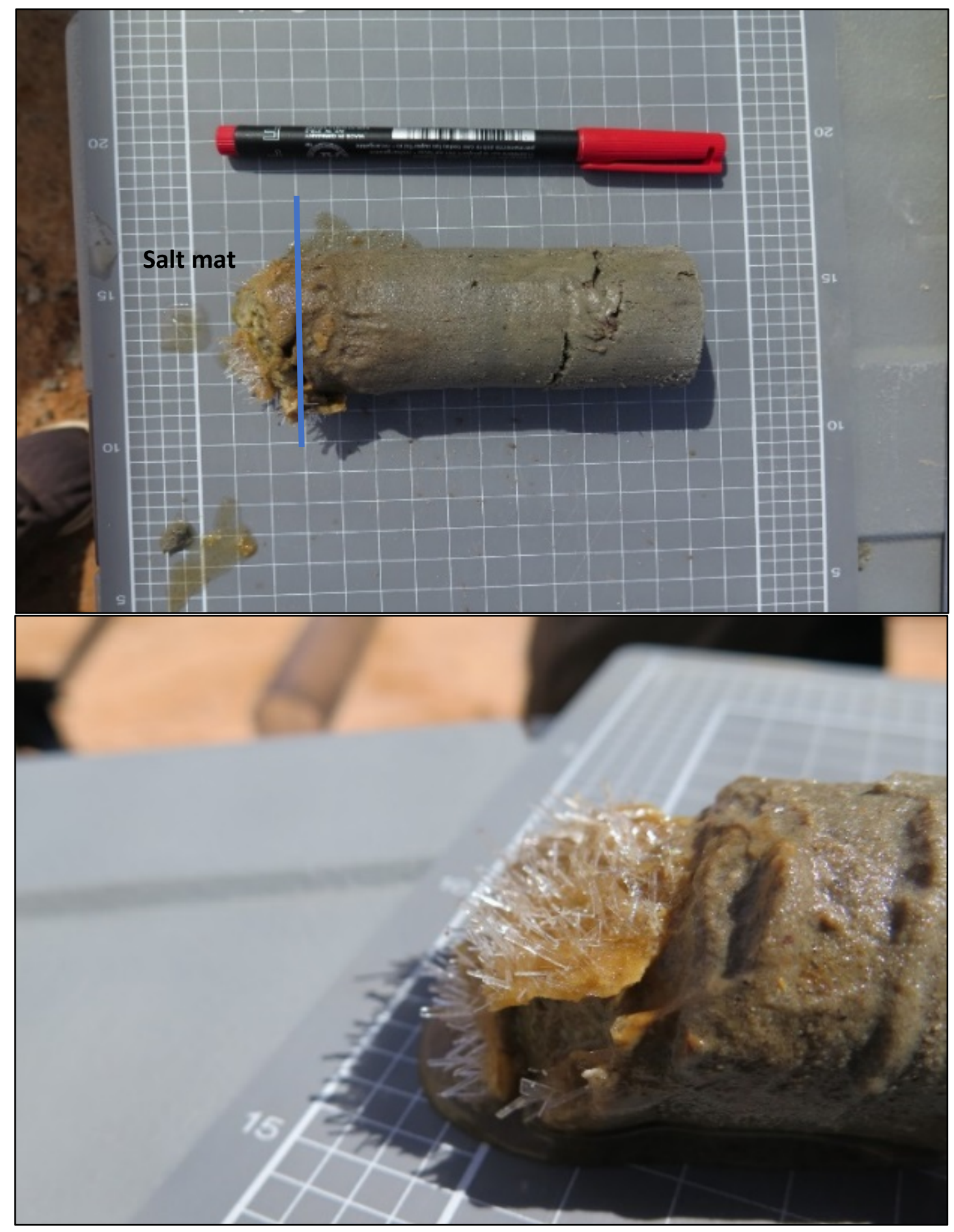




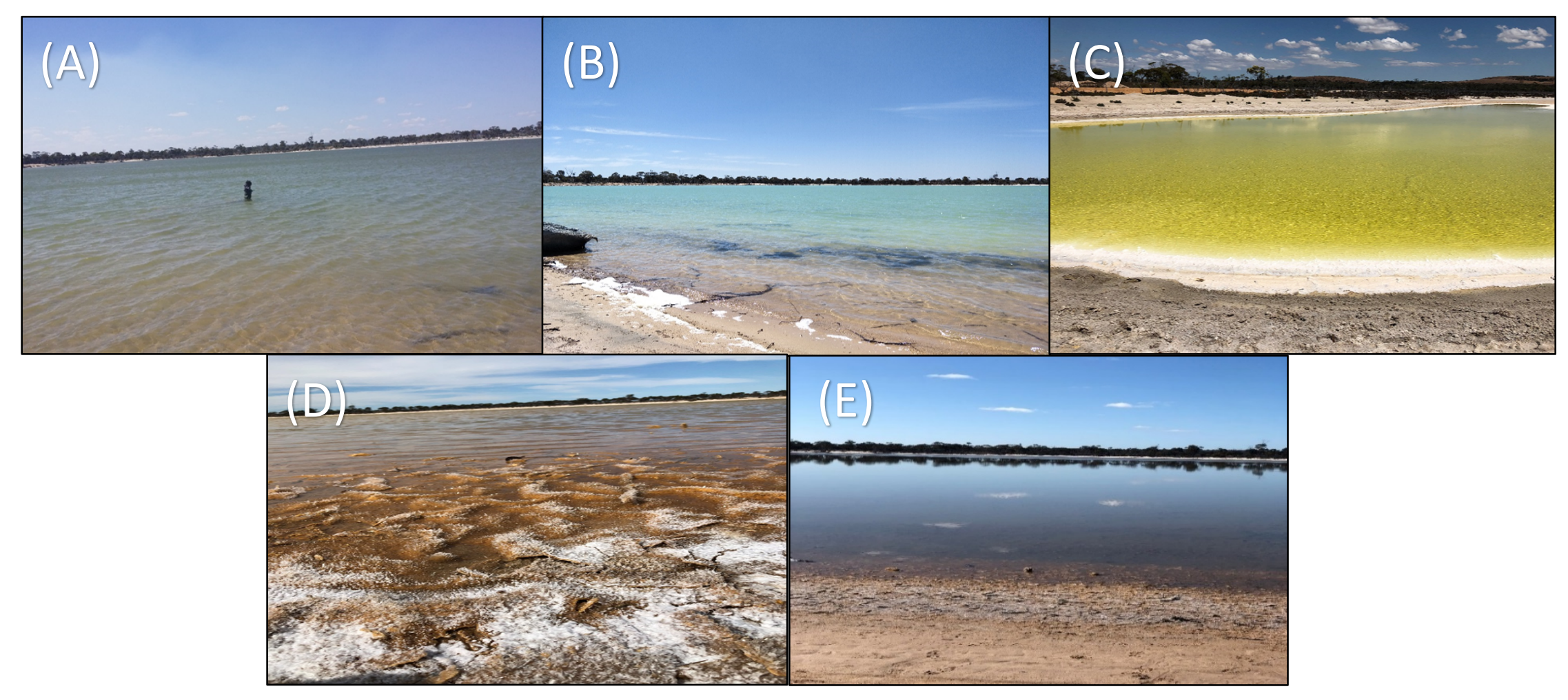


bioRxiv preprint doi: https://doi.org/10.1101/2020.12.17.423355; this version posted December 18, 2020. The copyright holder for this preprint (which was not certified by peer review) is the author/funder. All rights reserved. No reuse allowed without permission.
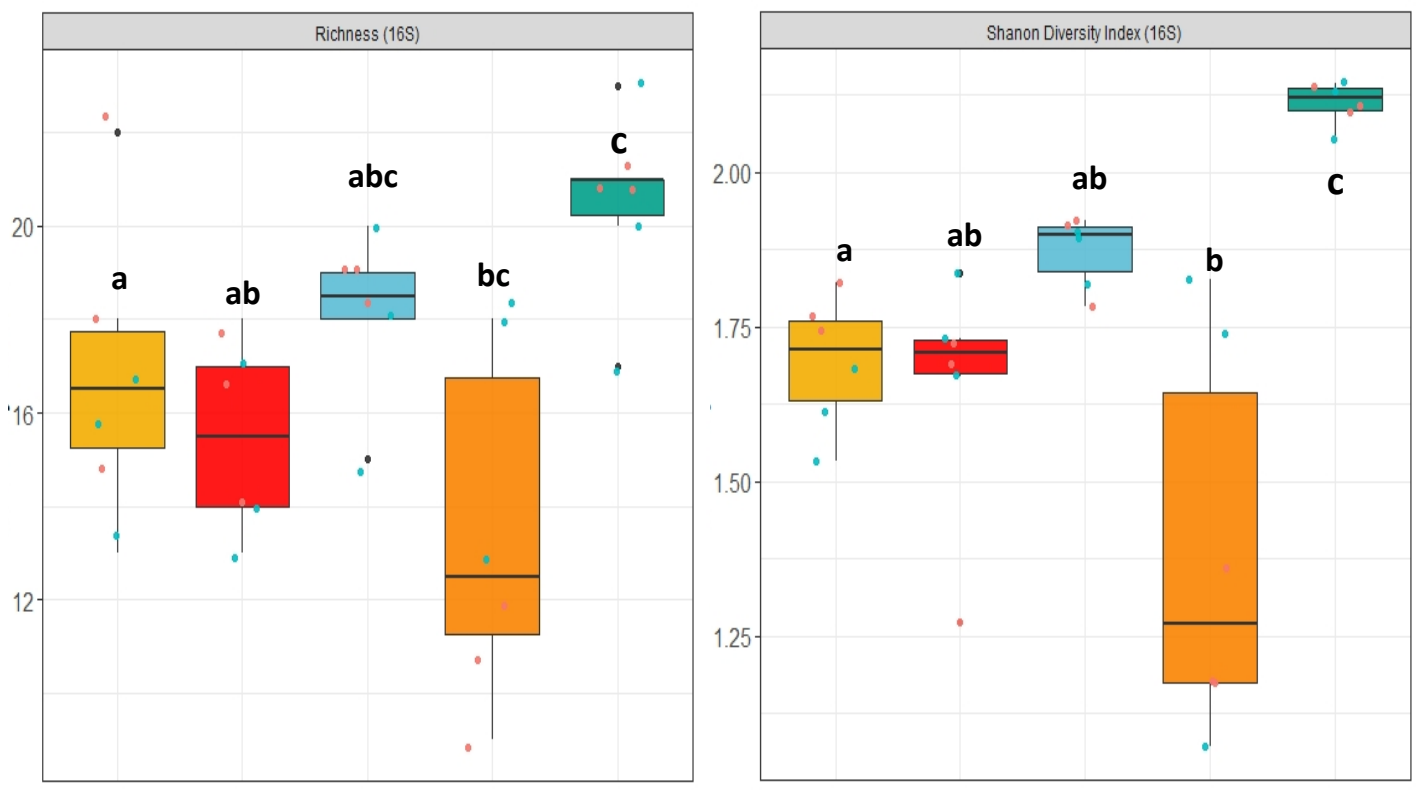

Figure $3 A$ and $3 B$
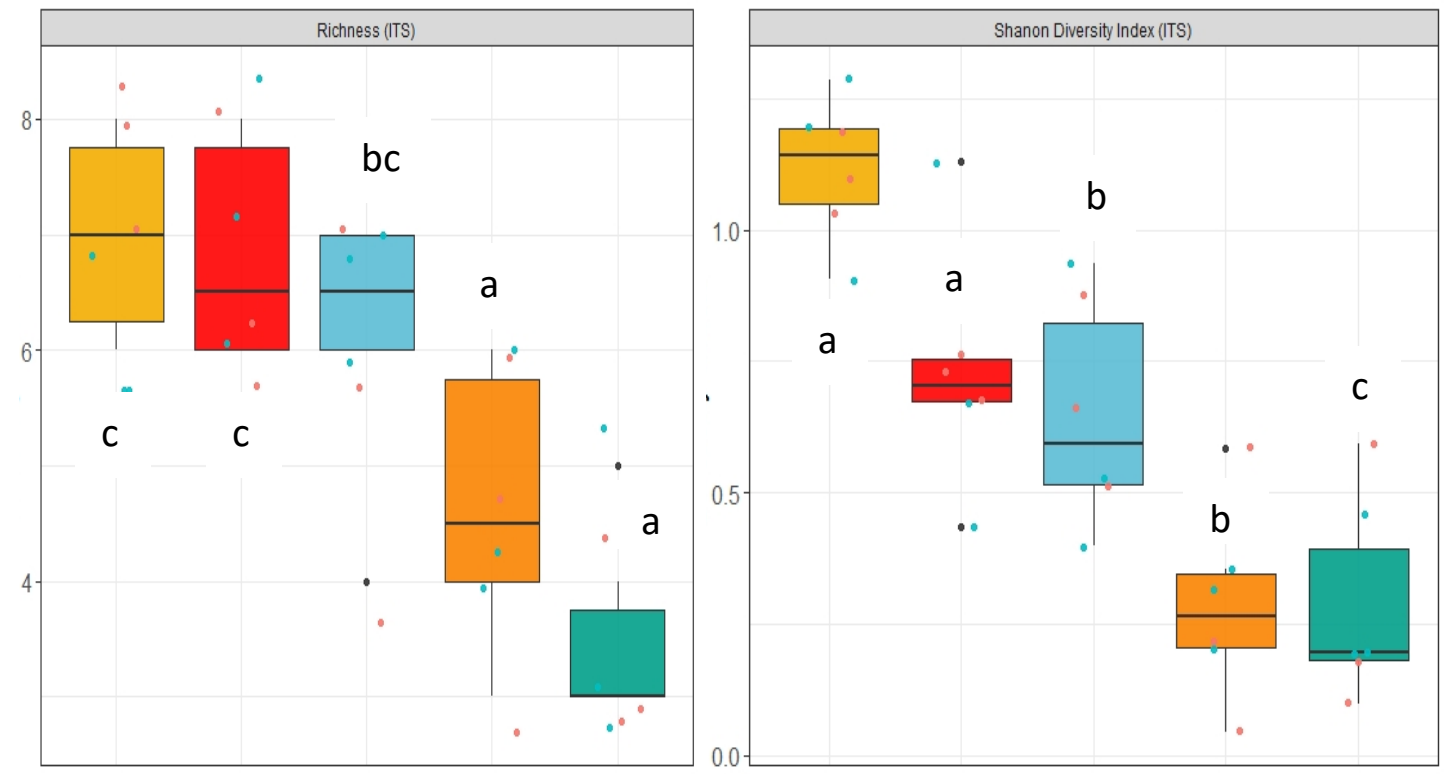

Figure 4A and 4B 
bioRxiv preprint doi: https://doi.org/10.1101/2020.12.17.423355; this version posted December 18, 2020. The copyright holder for this preprint (which was not certified by peer review) is the author/funder. All rights reserved. No reuse allowed without permission.

Figure 5A and 5B

A

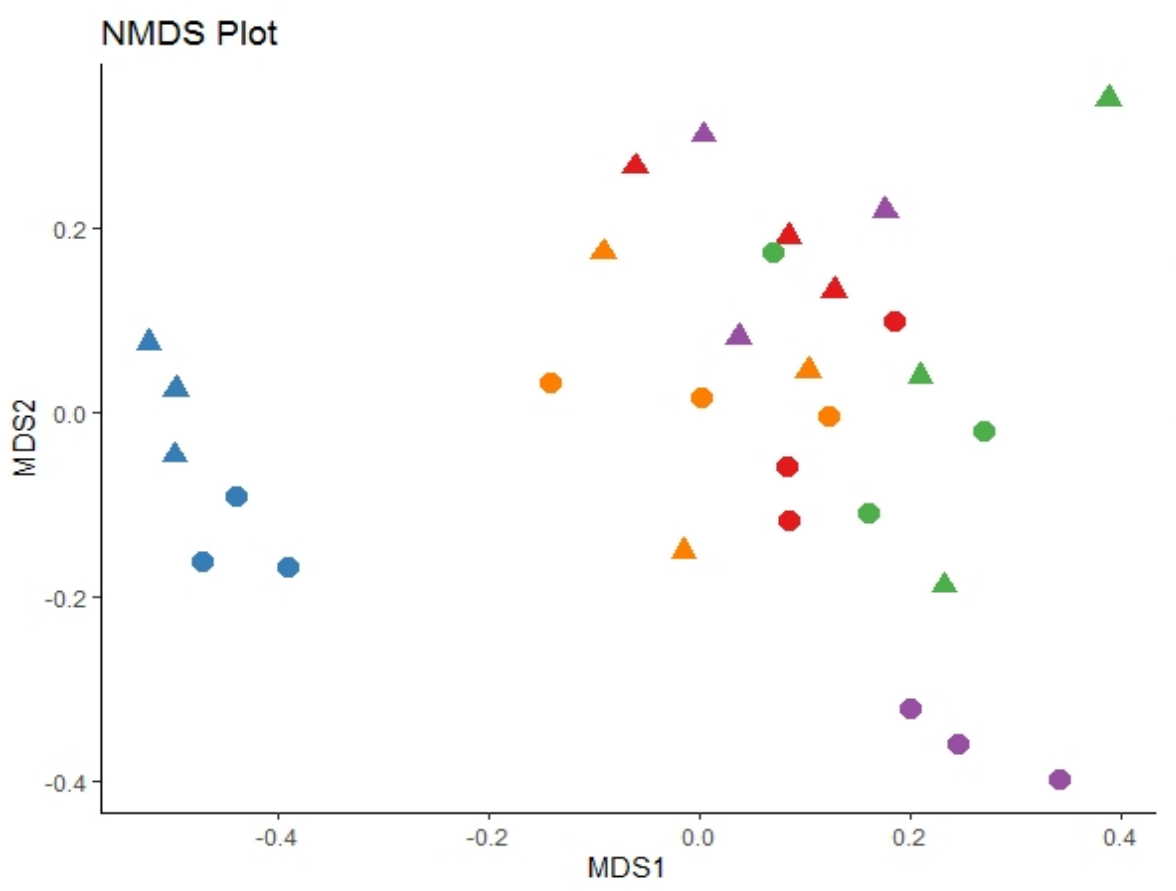

B

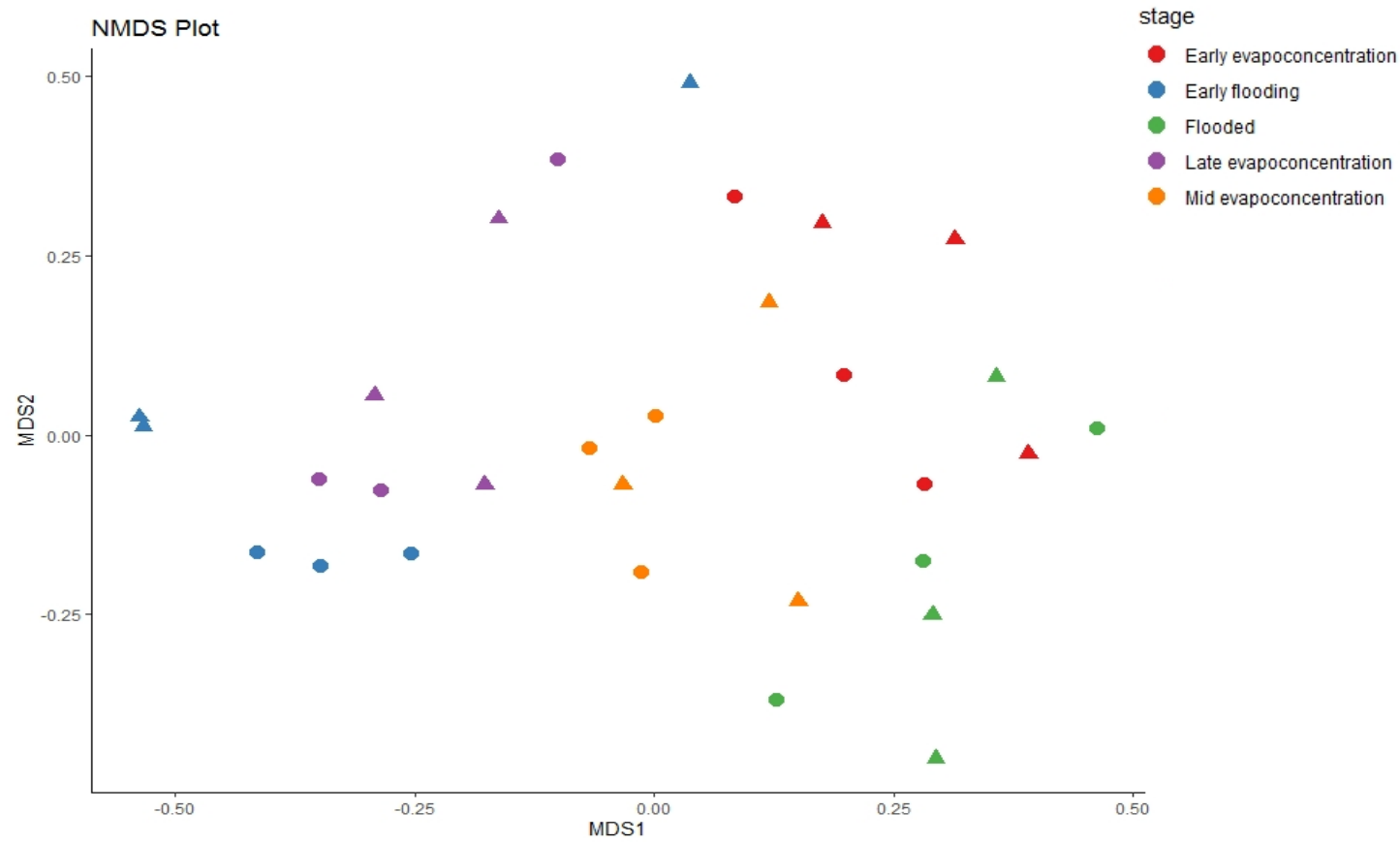

layer

salt mat

sediment

Early flooding

Flooded

Late evapoconcentration

Mid evapoconcentration 
bioRxiv preprint doi: https://doi.org/10.1101/2020.12.17.423355; this version posted December 18, 2020. The copyright holder for this preprint (which was not certified by peer review) is the author/funder. All rights reserved. No reuse allowed without permission. 